\title{
Consenso em paracoccidioidomicose
}

\author{
Guideliness in paracoccidioidomycosis
}

\author{
Maria Aparecida Shikanai-Yasuda ${ }^{1}$, Flávio de Queiroz Telles Filho ${ }^{2}$, \\ Rinaldo Pôncio Mendes ${ }^{3}$, Arnaldo Lopes Colombo ${ }^{4}$, Maria Luiza Moretti ${ }^{5}$ \\ e Grupo de Consultores do Consenso em Paracoccidioidomicose*
}

\section{INTRODUÇÃo}

Micose sistêmica endêmica de grande interesse para os países da América Latina, a paracoccidioidomicose (PCM) é causada pelo fungo termo-dimórfico Paracoccidioides brasiliensis. Apresenta distribuição heterogênea, havendo áreas de baixa e alta endemicidade. No adulto, a forma clínica predominante é a crônica, mas quando acomete crianças ou adolescentes apresenta-se na forma aguda ou subaguda. Quando não diagnosticada e tratada oportunamente, pode levar a formas disseminadas graves e letais, com rápido e progressivo envolvimento dos pulmões, tegumento, gânglios, baço, fígado e órgãos linfóides do tubo digestivo.

De acordo com dados de inquéritos epidemiológicos realizados com paracoccidioidina no Brasil, Venezuela, Colômbia e Argentina, acredita-se que em torno de 50\% dos habitantes de zonas endêmicas tenham sido expostos ao agente desta micose. Felizmente, apenas uma proporção muito pequena de indivíduos expostos a $P$. brasiliensis desenvolve alguma manifestação clínica da micose. Esta micose representa um importante problema de Saúde Pública devido ao seu alto potencial incapacitante e à quantidade de mortes prematuras que provoca, principalmente para segmentos sociais específicos, como os trabalhadores rurais, que além de tudo isso apresentam grandes deficiências de acesso e suporte da rede dos serviços de saúde favorecendo o diagnóstico tardio. A faixa etária mais acometida situa-se entre 30 e 50 anos de idade e mais de $90 \%$ dos casos são do sexo masculino. Os indivíduos acometidos pela micose, usualmente encontram-se na fase mais produtiva da vida, sendo que a doença leva a impacto social e econômico.
Este documento tem como objetivo estabelecer as diretrizes para o consenso da abordagem clínica, diagnóstica e tratamento da PCM, visando subsidiar os profissionais da saúde no atendimento primário e secundário da doença.

\section{ECOEPIDEMIOLOGIA}

Na natureza, $P$. brasiliensis apresenta-se como estruturas filamentosas contendo propágulos infectantes chamados conídios. Uma vez inalados, os propágulos dão origem a formas leveduriformes do fungo que constituirão sua forma parasitária nos tecidos do hospedeiro. Até recentemente, os humanos eram tidos como os únicos hospedeiros naturalmente infectados por este fungo. Atualmente, alguns animais foram encontrados portadores da infecção, como o tatu.

Ao longo das últimas décadas, têm sido observadas notáveis alterações na frequiência, nas características demográficas da população atingida e na distribuição geográfica da PCM. Dependendo da região, a incidência se alterou, sem que se possam justificar totalmente as suas causas. É possível que o aumento da urbanização e melhoria do diagnóstico expliquem, em parte, estas alterações. Além disto, fatores ambientais decorrentes da abertura de novas fronteiras agrícolas, com a derrubada de florestas, sobretudo nas regiões Centro-Oeste e Norte, atingindo marcadamente a Amazônia, também contribuíram para o atual panorama da micose.

\section{Como é adquirida a infecção por $P$. brasiliensis?}

0 grande fator de risco para aquisição da infecção são as profissões ou atividades relacionadas ao manejo do solo

\footnotetext{
1.Departamento de Moléstias Infecciosas e Parasitárias da Faculdade de Medicina da Universidade de São Paulo, São Paulo, SP. 2. Departamento de Saúde Comunitária da Universidade Federal do Paraná, Curitiba, PR. 3. Departamento de Doenças Tropicais e Diagnóstico por Imagem da Faculdade de Medicina Botucatu da Universidade Estadual de São Paulo, São Paulo, SP. 4. Departamento de Medicina da Escola Paulista de Medicina, São Paulo, SP. 5. Departamento de Clínica Médica da Faculdade Ciências Médicas da Universidade Estadual de Campinas, Campinas, SP.

*Consultores do Consenso em Paracoccidioidomicose: Adriana Kono, Antonia Terezinha Tresoldi, Bodo Wanke, Carlos Roberto Carvalho, Gil Benard, Luiz Carlos Severo, Marcelo Simão Ferreira, Mario Leon Silva Vergara, Roberto Martinez, Rogério Jesus Pedro, Silvio Alencar Marques, Zarifa Khoury.

Patrocínio sem conflito de interesse com entidades privadas: Sociedade Brasileira de Medicina Tropical, Sociedade Brasileira de Infectologia e Sociedade Paulista de Infectologia. Endereço para correspondência: Dra. Maria Aparecida Shikanai-Yasuda. Laboratório de Imunologia. Av. Enéias de Carvalho Aguiar 500, Térreo, Sala 4, 05403-000 São Paulo, Brasil.

Tel: 11 3066-7048, Fax:11 3069-7507

e-mail: lim48imuno@yahoo.com.br

Recebido para publicação em 20/5/2006

Aceito em 2/6/2006
} 
contaminado com o fungo, como por exemplo, atividades agrícolas, terraplenagem, preparo de solo, práticas de jardinagens, transporte de produtos vegetais, entre outros. Em todas as casuísticas, observa-se que a grande maioria dos pacientes exerceu atividade agrícola nas duas primeiras décadas de vida, tendo nessa época provavelmente adquirido a infecção, embora as manifestações clínicas tenham surgido muitos anos depois. A maioria destes pacientes, quando procuram atenção médica, já saíram da área endêmica, residindo em centros urbanos onde exercem outras atividades, não ligadas ao trato do solo. Tabagismo e alcoolismo estão freqüentemente associados à micose. Ao contrário de outras micoses, como a criptococose, a histoplasmose disseminada e a candidíase, a PCM não é usualmente relacionada a doenças imunodepressoras. Entretanto, há casos desta micose associados à infecção pelo HIV, neoplasias e, mais raramente, a transplantes de órgãos.

\section{Incidência, prevalência e mortalidade}

Uma vez que a PCM não é doença de notificação compulsória, não temos dados precisos sobre sua incidência no Brasil. Os cálculos de prevalência, incidência e morbidade da micose baseiam-se em relatos de inquéritos epidemiológicos e de séries de casos. Com base na experiência de serviços de referência no atendimento de pacientes com PCM, acredita-se que sua incidência em zonas endêmicas varie de 3 a 4 novos casos/milhão até 1 a 3 novos casos por 100 mil habitantes ao ano. Informações registradas no Ministério da Saúde atestam que 3.181 casos de óbito por PCM foram registrados no Brasil entre 1980 a 1995, resultando em taxa de mortalidade por PCM de 1,45 casos por milhão de habitantes. Neste estudo, os autores apontaram a PCM como oitava causa de mortalidade por doença infecciosa predominantemente crônica entre as doenças infecciosas e parasitárias, inclusive maior que a mortalidade por leishmanioses, e a mais alta taxa entre as micoses sistêmicas (Figura 1).

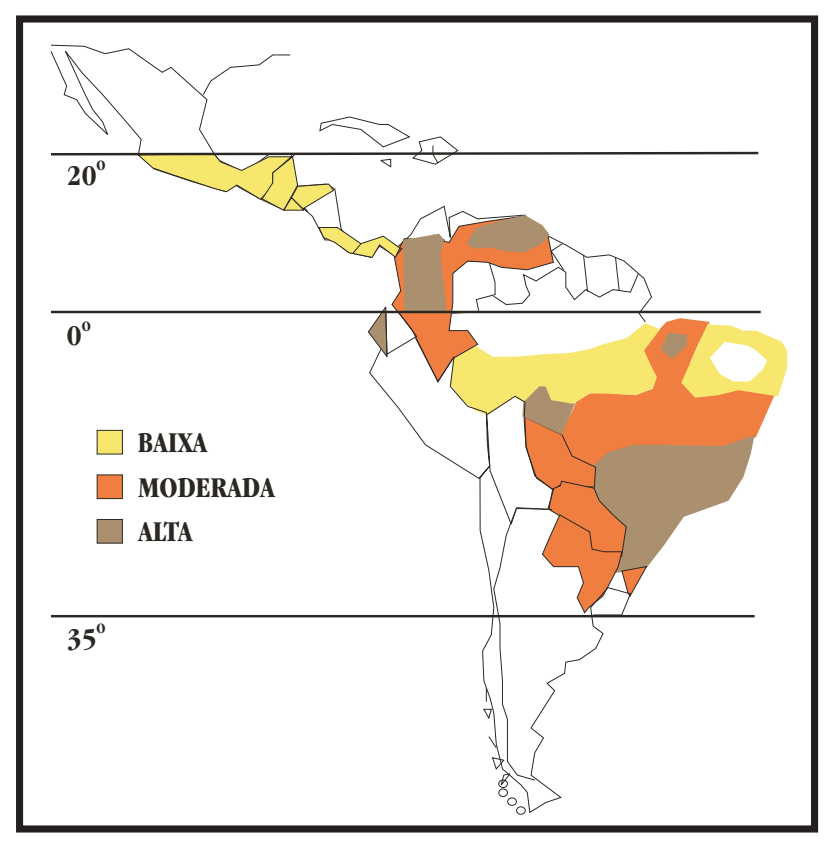

Figura 1 - Distribuição geográfica da paracoccidioidomicose.

\section{Faixa etária e distribuição entre gêneros}

A infecção é prioritariamente adquirida nas duas primeiras décadas de vida, com um pico de incidência entre 10 e 20 anos de idade. A apresentação de manifestações clínicas ou a evolução para doença é incomum neste grupo, ocorrendo mais freqüentemente em adultos entre 30 e 50 anos, como reativação de foco endógeno latente. Embora haja grandes variações entre as regiões, na média estima-se que cerca de $10 \%$ dos casos da doença ocorram até os 20 anos de idade e os demais ocorram em idade mais avançada. A razão de acometimento da PCM em adultos varia entre 10 a 15 homens para 1 mulher, o que não ocorre na infância, onde a infecção e a doença se distribuem uniformemente entre ambos os sexos, com ligeiro predomínio do masculino em adultos jovens.

\section{IMUNOPATOGENIA}

O controle da infecção depende de resposta imune celular efetiva, geralmente associada ao padrão tipo $1 \mathrm{da}$ resposta imunológica, caracterizado pela síntese de citocinas que ativam macrófagos e linfócitos T CD4+ e CD8+, resultando na formação de granulomas compactos. A organização desta resposta imune celular permite o controle da replicação do fungo, mas formas quiescentes podem persistir no interior do granuloma. Pacientes infectados que evoluem para doença apresentam depressão da resposta tipo 1, alteração esta que se correlaciona com a gravidade da doença. Neste contexto, formas mais graves evoluem com predomínio de resposta imunológica tipo 2, onde há maior ativação de linfócitos $\mathrm{B}$, hipergamaglobulinemia e altos títulos de anticorpos específicos, cuja magnitude, em geral, correlaciona-se positivamente com a gravidade e disseminação da doença. Esta observação é corroborada pelo encontro de queda importante do número de linfócitos CD4 nos pacientes portadores de formas mais graves desta micose.

0 conhecimento das alterações na resposta imunológica do hospedeiro induzido pela infecção é de relevância clínica para compreender-se a necessidade de tratamento prolongado, até o estabelecimento de uma eficiente resposta imune celular. Da mesma forma, uma vez que pode ocorrer a persistência de células leveduriformes quiescentes no interior de granulomas, por razões ainda não completamente estabelecidas, pode haver recidivas da doença. Não se demonstrou o papel protetor em relação aos altos níveis séricos de anticorpos específicos das classes $\operatorname{IgA}$, IgE, e IgG em pacientes com formas mais disseminadas.

\section{CLASSIFICAÇÃO DAS FORMAS CLÍNICAS E AVALIAÇÃO DE GRAVIDADE}

Diversas classificações das formas clínicas da PCM foram publicadas desde a descrição da doença. Todas elas baseavam-se em diferentes critérios tais como topografia das lesões, gravidade da doença, resultados de reações 
sorológicas e história natural, entre outros. Com o objetivo de propor uma classificação de formas clínicas e gravidade da doença, factível de utilização pelo clínico, neste consenso adotou-se uma adaptação da classificação apresentada no International Colloquium on Paracoccidioidomycosis realizado em fevereiro de 1986 em Medellín, Colômbia, que correlaciona dados clínicos à história natural da moléstia.

\author{
Classificação das formas clínicas da PCM \\ - Paracoccidioidomicose infecção \\ - Paracoccidioidomicose doença \\ - Forma aguda/subaguda \\ - Forma crônica \\ - Unifocal \\ - Multifocal \\ - Forma residual ou sequelar
}

\section{Forma aguda/subaguda (tipo juvenil)}

Esta forma de apresentação clínica é responsável por 3 a $5 \%$ dos casos da doença, predominando em crianças e adolescentes, mas podendo eventualmente, acometer indivíduos até os 35 anos de idade. A distribuição da forma aguda / subaguda é semelhante em crianças dos gêneros masculino e feminino. Esta forma clínica caracteriza-se por evolução mais rápida, onde o paciente geralmente procura o serviço médico entre 4 a 12 semanas de instalação da doença. Em ordem de freqüência, podemos destacar a presença de linfadenomegalia, manifestações digestivas, hepatoesplenomegalia, envolvimento ósteo-articular e lesões cutâneas como as principais formas de apresentação desta forma da micose. Figuras 2 e 3.

\section{Forma crônica (tipo adulto)}

Esta forma clínica responde por mais de $90 \%$ dos pacientes, e apresenta-se principalmente em adultos entre os 30 e 60 anos, predominantemente, do sexo masculino. A doença progride lentamente, de forma silenciosa, podendo levar anos até que seja diagnosticada. As manifestações pulmonares estão presentes em $90 \%$ dos pacientes. É chamada de apresentação unifocal quando a micose está restrita a somente um órgão. Os pulmões podem ser o único órgão afetado em até $25 \%$ dos casos. Geralmente, a doença envolve mais de um órgão simultaneamente (apresentação multifocal), sendo pulmões, mucosas e pele os sítios mais acometidos pela infecção.

A avaliação imunológica, se possível, deverá ser realizada em todas as variedades clínicas e poderá trazer valiosas informações acerca do prognóstico e da atividade da doença, essenciais para o acompanhamento clínico e controle de cura da micose. Os critérios de gravidade (leve, moderado e grave) podem auxiliar no planejamento da terapêutica do paciente. Os critérios de gravidade são subjetivos, podendo variar conforme a análise individual do clínico à beira do leito, segundo a sua ótica.

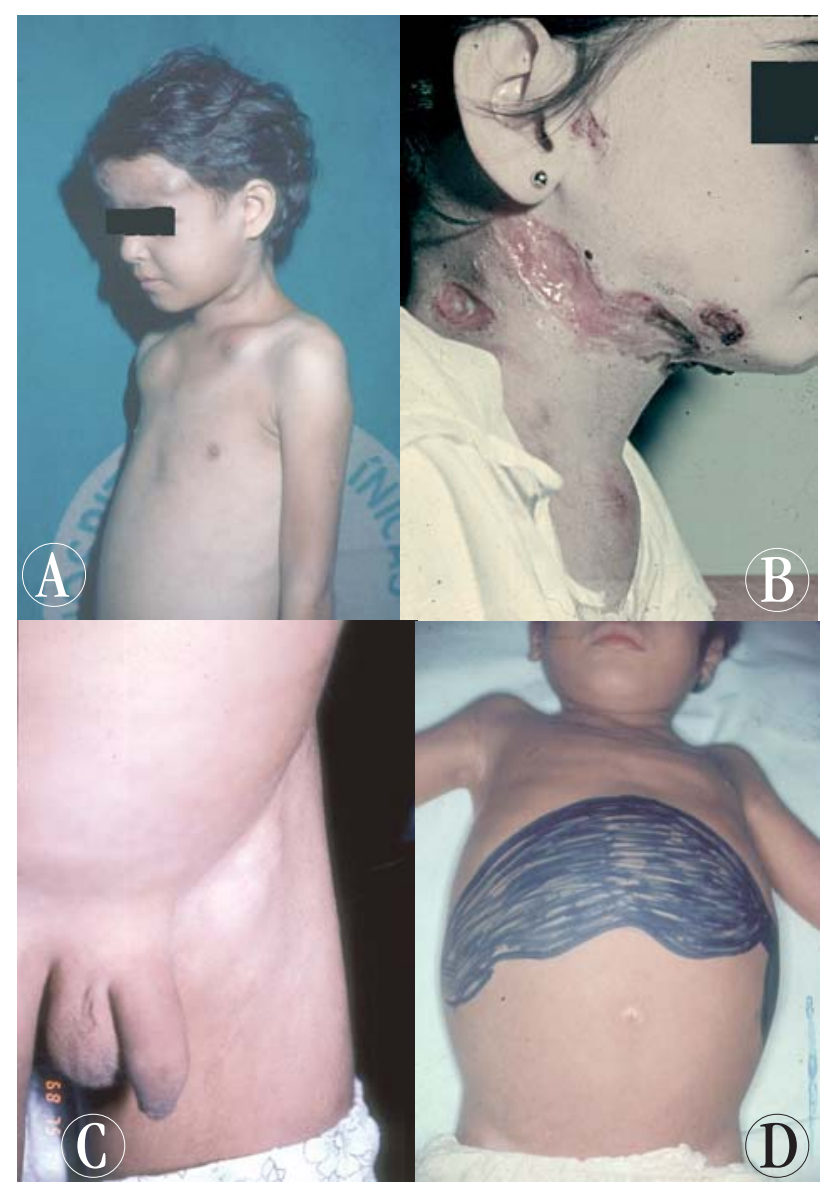

Figura 2 - Crianças apresentando a forma aguda da paracoccidioidomicose. A- Notar abscessos em regióes frontal e clavicular, resultantes do acometimento osteo-articular. B - Criança do sexo feminino apresentando importante acometimento linfático abscedado. C - Linfoadenomegalia inguinal. D-Acometimento linfáticoabdominal com ascite e hepato-esplenomegalia.

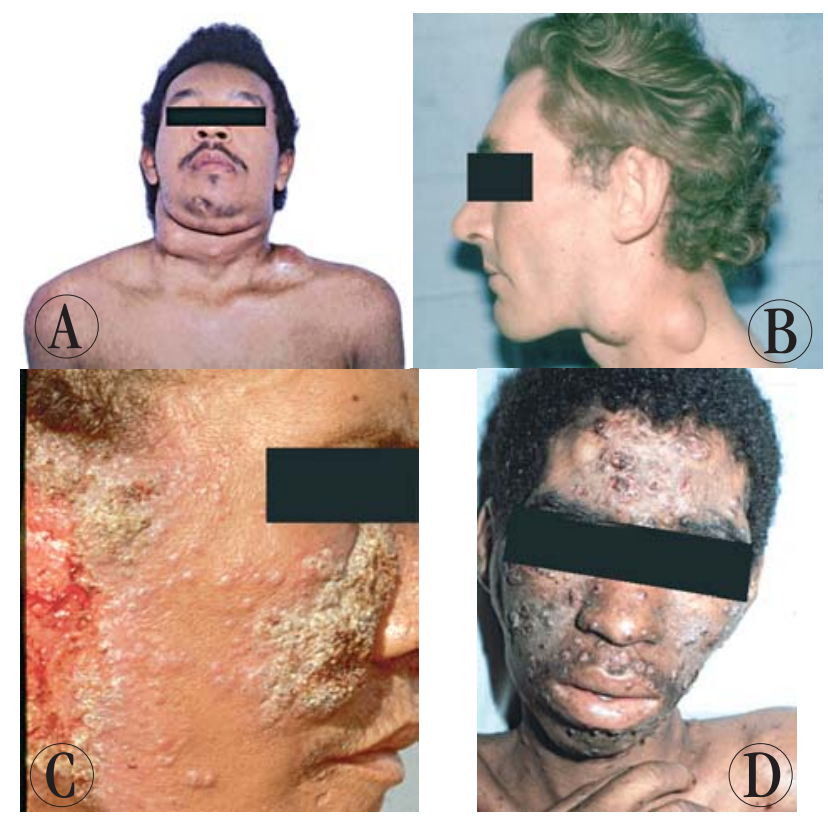

Figura 3 - Jovens com a forma aguda/subaguda (tipo juvenil) da paracoccidioidomicose. $A$ - Massas ganglionares em região supraclavicular, cervical e submandibular. $\boldsymbol{B}$ - A linfoadenomegalia da paracoccidioidomicose deve ser diferenciada de doenças hematológicas, como linfoma. $C$ - Lesões ulceradas em face e pavilhão auricular, de aspecto verruciforme resultante de disseminação hematogênica. $D$ - Lesões de aspecto pápulo-nodular $\mathrm{e}$ ulceradas, todas resultantes de disseminação hematogênica. 
Entretanto, alguns parâmetros devem ser utilizados para enquadrar de maneira correta cada doente dentro da classificação (comprometimento do estado geral, perda de peso, tipo de linfadenopatia supurada ou não e gravidade do envolvimento pulmonar). As seqüelas caracterizam-se pelas manifestações cicatriciais que se seguem ao tratamento da micose. Figuras 4 a 6 .

\section{ATENDIMENTO INICIAL, ABORDAGEM DIAGNÓSTICA E ROTINA DE SEGUIMENTO AMBULATORIAL DE PACIENTES COM PCM}

Sendo a PCM uma micose sistêmica, qualquer sítio orgânico pode ser acometido. A atenção do observador deve ser inicialmente dirigida ao estado geral do paciente e então, aos órgãos e sistemas que são mais freqüentemente comprometidos segundo as formas de apresentação da doença: PCM aguda/subaguda e PCM crônica. Conforme rotina habitual de atendimento médico, todos os pacientes
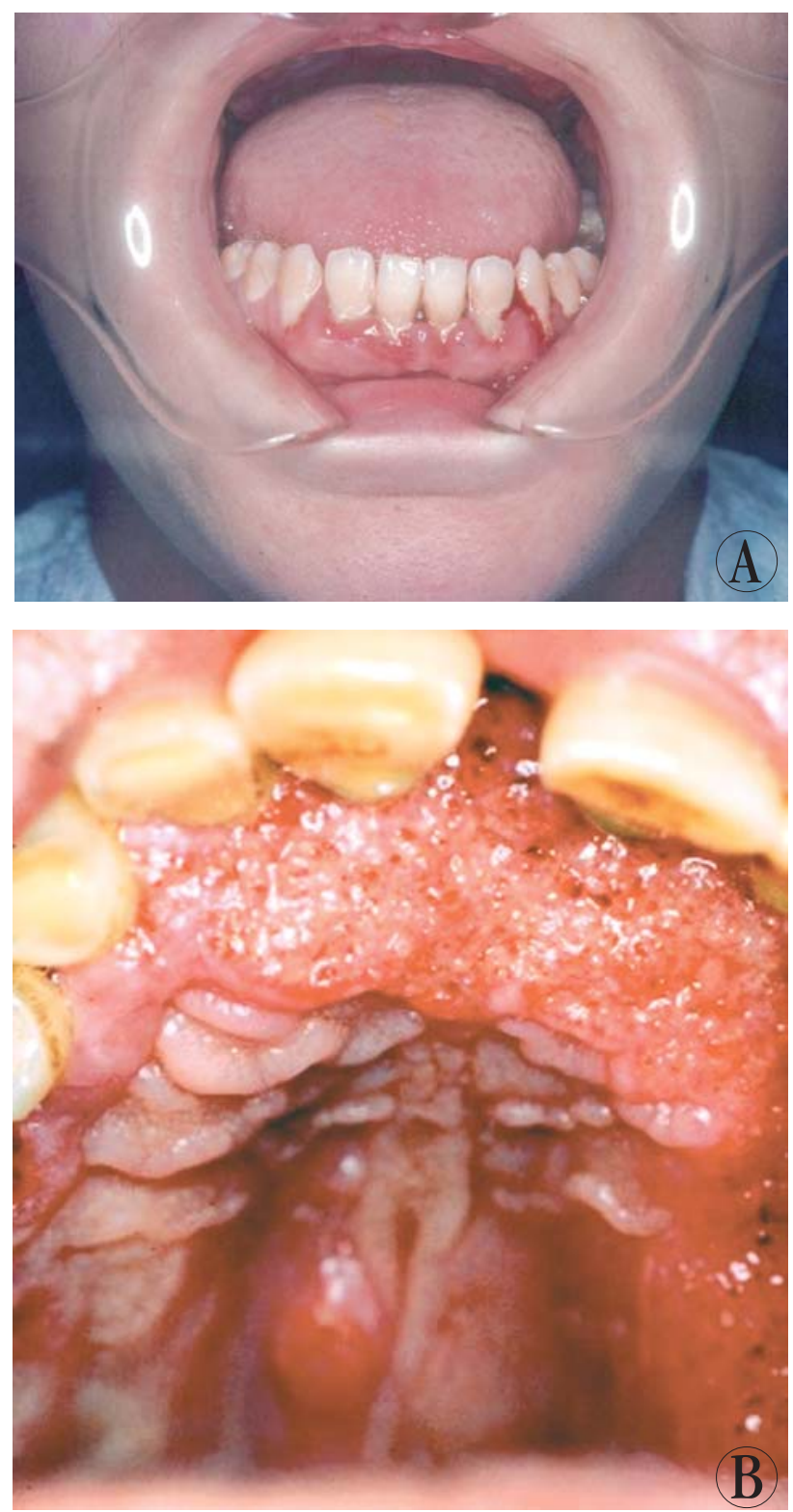

Figura 4 - Acometimento oral na forma crônica da paracoccidioidomicose. A - Gengivoestomatite B - Estomatite moriforme

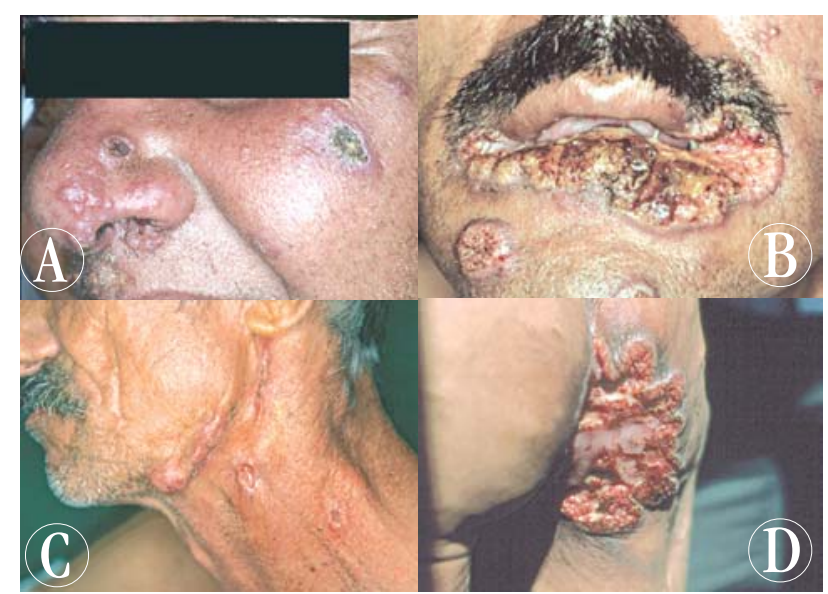

Figura 5 - Aspectos clínicos da forma crônica da paracoccidioidomicose. A - Lesões cutâneas em face resultantes de disseminação hematogênica. Lesões papulosas e úlcero-crostosas. B - Acometimento peri-oral e mentoniano. $C$ - Linfonodos cervicais e submandibulares fistulizados. D - Lesão vegetante com bordos irregulares em região peri-anal.

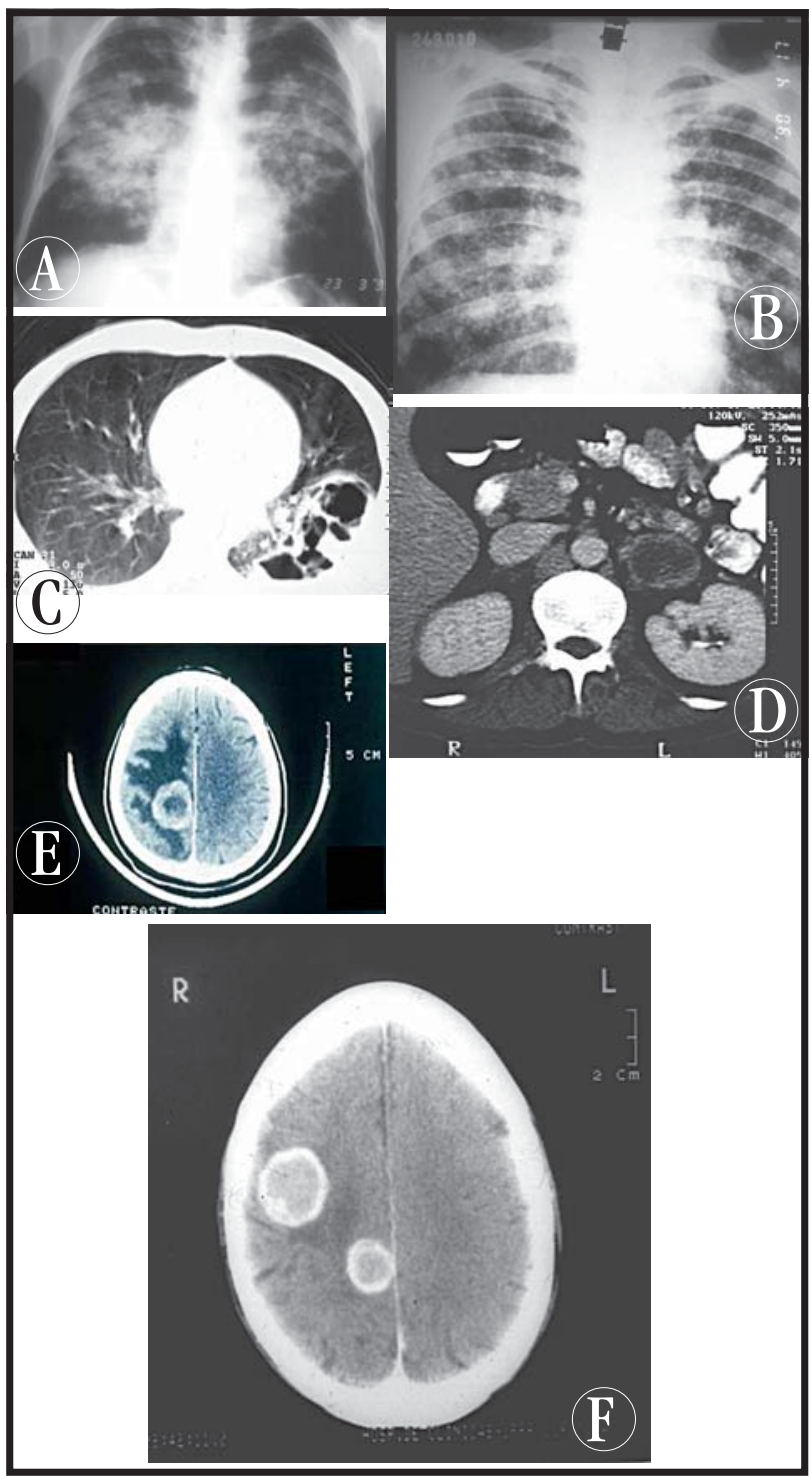

Figura 6 - Imagens em paracoccidioidomicose. A - Radiologia convencional mostrando imagem em "asa de borboleta". B - opacidades nodulares e micronodulares difusas . C - Tomografia de pulmão apresentando múltiplas cavitações. $D$ - Aumento bilateral de adrenais. $\boldsymbol{E}$ e $\boldsymbol{F}$ - $O$ envolvimento de $S N C$ evidencia imagens de aspecto hipodenso e com realce de contraste em forma de anel. 
devem ter exame físico geral detalhado, lembrando-se de relatar avaliação de peso e altura, para permitir a caracterização do estado nutricional.

\subsection{Avaliação geral de paciente com forma aguda}

$\mathrm{Na}$ forma aguda, a anamnese e o exame físico devem ser dirigidos para pesquisar o envolvimento de múltiplas cadeias de linfonodos e suas possíveis complicações: icterícia obstrutiva por compressão de colédoco, sub-oclusão ou oclusão intestinal (eventualmente também secundária a lesões de mucosa), síndrome de compressão de veia cava, diarréia com síndrome de má absorção e ascite. Além da avaliação de múltiplas cadeias de linfonodos, incluir a pesquisa de hepatomegalia, esplenomegalia, lesões de pele, lesões ósteoarticulares, sinais e sintomas relacionados ao envolvimento adrenal (astenia, emagrecimento, hipotensão arterial, hiperpigmentação de pele, dores abdominais) e sistema nervoso central (cefaléia, déficit motor, síndrome convulsivo, alteração de comportamento e/ou nível de consciência).

\section{Exames laboratoriais e de imagem}

Raio X simples de tórax (PA e Perfil)

Ultrassonografia abdominal

Hemograma completo

Velocidade de hemossedimentação

Provas bioquímicas hepáticas: ALT, AST, gGT, fosfatase alcalina

Eletroforese de proteínas

Avaliação renal e metabólica: creatinina, Na e $K$

A realização de exames mais complexos está condicionada à suspeita clínica ou alterações dos exames laboratoriais que indiquem envolvimento de sistema nervoso central, acometimento gastrointestinal, disfunção adrenal, insuficiência respiratória ou lesões ósteo-articulares. Nestes pacientes, a investigação com exames de imagem e provas funcionais deverá ser conduzida com o apoio de especialistas, no ambiente hospitalar. A realização de exames mais complexos está condicionada à suspeita clínica ou alterações dos exames laboratoriais que indiquem o envolvimento do sistema nervoso central, acometimento do sistema gastrintestinal, disfunção adrenal, lesões ósteo-articulares, entre outros.

\subsection{Avaliação geral de paciente com forma crônica}

$\mathrm{Na}$ forma crônica, a anamnese e o exame físico devem obrigatoriamente incluir a pesquisa de sinais e sintomas relacionados ao envolvimento pulmonar, tegumentar e laringeo (tosse, dispneia, expectoração muco/purulenta, lesões ulceradas de pele e de mucosa da naso-orofarínge, odinofagia, disfagia; disfonia, etc), linfático (adenomegalia), adrenal (astenia, emagrecimento, hipotensão, escurecimento de pele, dores abdominais) e, sistema nervoso central (cefaléia, déficit motor, síndrome convulsivo, alteração de comportamento e/ou nível de consciência).

Exames laboratoriais e de imagem para avaliação da doença

Raio X simples de tórax (PA e Perfil)

Hemograma completo

Velocidade de hemossedimentação (VHS)

Provas bioquímicas hepáticas: ALT, AST, gGT, fosfatase alcalina

Avaliação renal e metabólica: creatinina, Na e $K$

A realização de exames mais complexos está condicionada à suspeita clínica ou alterações dos exames laboratoriais que indiquem envolvimento de sistema nervoso central, acometimento gastrointestinal, formas abdominais, disfunção adrenal, insuficiência respiratória crônica ou lesões ósteo-articulares. Nestes pacientes, a investigação com exames de imagem e provas funcionais deverá ser conduzida com o apoio de especialistas, se necessário, no ambiente hospitalar.

\subsection{Exames laboratoriais para diagnóstico específico}

0 padrão ouro para o diagnóstico de PCM é o encontro de elementos fúngicos sugestivos de $P$. brasiliensis em exame a fresco de escarro ou outro espécime clínico (raspado de lesão, aspirado de linfonodos) e/ou fragmento de biopsia de órgãos supostamente acometidos.Aspectos do diagnóstico laboratorial da doença podem ser observados na Figura 7.

Para fins de possível notificação padronizada de casos, sugerem-se as seguintes definições:

1. Caso suspeito: paciente com uma ou mais das seguintes manifestações, durante pelo menos quatro semanas, excluída a tuberculose e outras doenças que cursam com quadro semelhante:

1.1. Tosse com ou sem expectoração e dispnéia

1.2. Sialorréia, odinofagia, rouquidão

1.3. Lesão (ulcerada) na mucosa nasal ou oral

1.4. Lesões cutâneas (úlceras, vegetações, nódulos, placas etc)

1.5. Adenomegalia cervical ou generalizada, com ou sem supuração e fistulização.

1.6. Criança ou adulto jovem com hepatoesplenomegalia e/ou tumoração abdominal.

2 - Caso provável: paciente com manifestações clínicas compatíveis com PCM e títulos de anticorpos séricos anti-P. brasiliensis realizado preferencialmente por imunodifusão quantitativa. A técnica de contra-imunoeletroforese é uma alternativa válida porém disponível em centros de referência. A técnica de ELISA não deve ser empregada pela sua inespecificidade na PCM. 
3 - Caso confirmado: Paciente com manifestações clínicas compatíveis com PCM em cuja secreção, fluido corporal ou material de lesão foi observado a presença de $P$. brasiliensis, por exame micológico direto, cultura ou exame histopatológico. Figura 7.
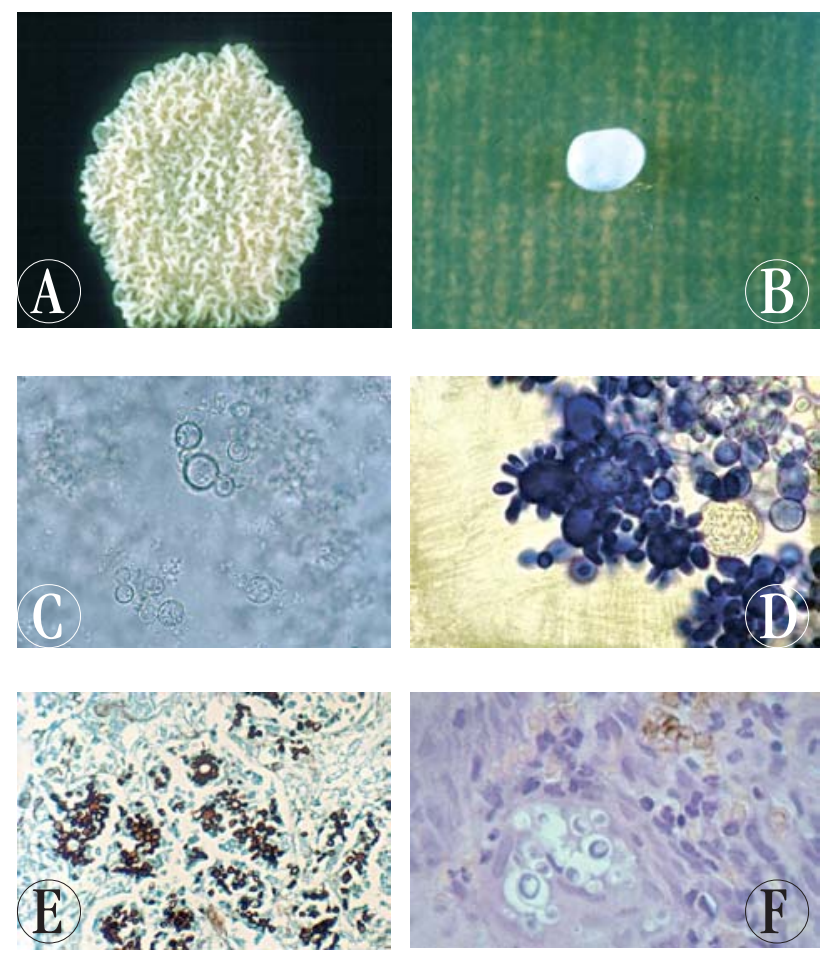

Figura 7 - Diagnóstico laboratorial da paracoccidioidomicose. Cultivo de P. brasiliensis. $A$ - fase micelial. $B$ - fase leveduriforme. $C$ - Exame a fresco em $\mathrm{KOH}$. D - corado pelo lactofenol mostrando células leveduriformes com múltiplos brotamentos. E - Corte histológico corado pelo método de Grocott. F-Corte histológico corado pelo PAS.

\subsection{Avaliação crítica de exames sorológicos: Diagnóstico e seguimento sorológico}

As provas sorológicas específicas têm importância não apenas no auxílio diagnóstico como, particularmente, para permitir avaliação da resposta do hospedeiro ao tratamento específico. Atualmente, são disponíveis em diferentes serviços de referência os métodos de imunodifusão dupla (ID), contraimunoeletroforese (CIE), imunofluorescência indireta (IFI), ensaio imunoenzimático (ELISA) e imunoblot (IB). Utilizando-se técnicas padronizadas e antígenos adequados, estes testes apresentam sensibilidade entre 85\% e 100\%. 0 título de anticorpos específicos anti-P. brasiliensis tem correlação com a gravidade das formas clínicas, sendo mais elevados na forma aguda-subaguda da doença. Casos de PCM com resultados falso-negativos, observados com quaisquer dos testes, na maioria das vezes se associam com lesões muito localizadas e com hospedeiros com aids ou imunodeprimidos. A especificidade dos testes sorológicos varia de $85 \%$ a valores próximos de $100 \%$, na dependência da técnica utilizada. Reações falso-positivas podem ocorrer com soros de pacientes com histoplasmose e aspergilose.
Tendo em vista a maior simplicidade do teste, a não necessidade de equipamentos de maior custo, a sensibilidade $>80 \%$ e a especificidade $>90 \%$, bem como pela experiência acumulada nas últimas décadas, a reação de imunodifusão dupla em gel agar situa-se atualmente como principal método de diagnóstico sorológico da PCM. Recomenda-se para ID ou qualquer outro teste utilizado no diagnóstico de PCM que os soros sejam titulados, para melhor interpretação da resposta terapêutica, uma vez que os títulos de anticorpos diminuem progressivamente com o controle clínico da doença. É desejável que ocorra negativação ou estabilização em diluição de 1:2 ou menos para considerar-se preenchido o critério de cura sorológica. Alguns pacientes podem apresentar já no diagnóstico títulos abaixo de 1:4. Nestes casos, o critério sorológico pela ID tem valor limitado no seguimento do tratamento.

Recursos adicionais para o sorodiagnóstico são encontrados apenas em centros de referência e/ou de pesquisa. O ELISA representa um método alternativo para o sorodiagnóstico da PCM, mais rápido e mais apropriado para exame de grande número de soros. É técnica mais sensível, porém sua especificidade é menor do que a da ID, exigindo cuidadosa padronização e interpretação dos resultados positivos. A reação de imunoblot permite especificar os tipos de anticorpos séricos contra os diversos determinantes antigênicos do fungo. Outra abordagem diagnóstica consiste na demonstração de anticorpos ou antígenos em outros fluídos, incluindo líquido cefalorraquiano, lavado bronco-alveolar e urina.

\subsection{Freqüência de retornos ambulatoriais e realização de exames}

Recomenda-se a realização de consultas médicas mensais nos 3 primeiros meses, para otimizar a adesão do paciente ao regime terapêutico instituído, avaliar a tolerabilidade ao medicamento e certificar-se de que houve boa resposta clínica. Havendo resposta clínica satisfatória, as consultas serão trimestrais até o final do tratamento. Após 90 de seguimento, em caso de resposta clínica satisfatória, os pacientes realizarão: hemograma e provas bioquímicas a cada 3 meses. Exames radiológicos e a sorologia deverão ser solicitados a cada 6 meses, ou em período menor se não houver resposta clínica satisfatória ou aparecerem alterações laboratoriais indicativas de atividade. A redução dos títulos de anticorpos específicos deverá ocorrer em torno de 6 a 10 meses após o tratamento, devendo negativar ou estabilizar em títulos baixos, após 10 meses. Após a interrupção do tratamento, uma vez observados os critérios de cura, os pacientes devem ser acompanhados ambulatorialmente, em consulta semestrais, ao longo do primeiro ano. Apos este período, permanecendo o paciente com critérios de cura, o mesmo deverá ter alta e orientado para retornar se necessário.

De acordo com a forma de apresentação clínica da PCM deverão ser solicitados exames de acompanhamento específicos, tais como ultra-som (ex. para avaliar a evolução de massas ganglionares ou imagens nodulares em órgãos 
abdominais); tomografia computadorizada ou ressonância magnética para avaliar as lesões encefálicas, etc. (Tabela 1).

Tabela 1 - Orientação para o seguimento clínico-laboratorial de pacientes com paracoccidioidomicose sob terapêutica.

\begin{tabular}{|c|c|c|}
\hline & $\begin{array}{l}\text { Acompanhamento do } \\
\text { paciente }\end{array}$ & \\
\hline $1^{\text {a }}$. Consulta & $\begin{array}{l}\text { Avaliação geral } \\
\text { do paciente }\end{array}$ & $\begin{array}{l}\text { Hemograma; VHS; ALT; } \\
\text { AST; gGT, fosfatase } \\
\text { alcalina, Na; K; sorologia } \\
\text { e RX de tórax }\end{array}$ \\
\hline 30 dias & $\begin{array}{l}\text { Consulta de } \\
\text { retorno }\end{array}$ & $\begin{array}{l}\text { Hemograma; VHS; ALT; } \\
\text { AST; gGT, fosfatase } \\
\text { alcalina, } \mathrm{Na} \text {; K. }\end{array}$ \\
\hline 60 dias & $\begin{array}{l}\text { Consulta de } \\
\text { retorno }\end{array}$ & $\begin{array}{l}\text { Hemograma; VHS; ALT; } \\
\text { AST; gGT, fosfatase } \\
\text { alcalina, Na; K } \\
\text { (RX de tórax e sorologia } \\
\text { se necessário ou má } \\
\text { resposta ao tratamento) }\end{array}$ \\
\hline 90 dias & $\begin{array}{l}\text { Consulta de } \\
\text { retorno }\end{array}$ & $\begin{array}{l}\text { Sorologia e RX de tórax. } \\
\text { Outros exames se } \\
\text { necessários. }\end{array}$ \\
\hline $\begin{array}{l}\text { Retornos a cada } \\
3 \text { meses durante } \\
\text { todo o tratamento }\end{array}$ & $\begin{array}{l}\text { Consulta de } \\
\text { retorno }\end{array}$ & $\begin{array}{l}\text { Hemograma; VHS; ALT; } \\
\text { AST; gGT, fosfatase } \\
\text { alcalina, Na; K } \\
\text { Cada } 6 \text { meses - realizar } \\
\text { sorologia e RX de tórax }\end{array}$ \\
\hline $\begin{array}{l}\text { Após interrupção do } \\
\text { tratamento, retornos } \\
\text { semestrais, durante um } \\
\text { ano. Após este período, } \\
\text { alta se paciente estável e } \\
\text { mantendo os critérios de } \\
\text { cura da doença }\end{array}$ & $\begin{array}{l}\text { Consulta de } \\
\text { retorno a cada } 6 \\
\text { meses (Total de } 2 \\
\text { consultas) }\end{array}$ & $\begin{array}{l}\text { Exames laboratoriais se } \\
\text { necessário }\end{array}$ \\
\hline
\end{tabular}

\subsection{Suporte clínico ambulatorial de especialidades}

Todos os pacientes com envolvimento de laringe (disfonia) e traquéia deverão ser submetidos a nasofibroscopia e seguimento clínico pelo otorrinolaringologista, para 0 reconhecimento precoce de quadros de estenose de laringe e estabelecimento de medidas terapêuticas necessárias. Pacientes que evoluam com dispnéia aos médios ou mínimos esforços, apesar da adesão regular a pelo menos 6 meses do tratamento instituído, deverão ser avaliados por pneumologista para tratamento de doença pulmonar obstrutiva crônica com orientação adequada da terapêutica e seguimento clínico de seqüela pulmonar.

\section{INDICAÇÕES DE INTERNAÇÃO}

\section{Deverão ser internados os seguintes pacientes:}

1 - Pacientes com formas disseminadas apresentando ao menos uma das seguintes complicações: alterações neurológicas, insuficiência respiratória, importante comprometimento do estado nutricional, envolvimento gastrointestinal, icterícia, ascite, alterações hemodinâmicas.

2 - Pacientes apresentando co-morbidades tais como aids, tuberculose e/ou neoplasia, se houver necessidade de melhor investigação diagnóstica ou mediante deterioração clínica.

3 - Pacientes com seqüelas e instabilidade clínica tais como DPOC descompensada, cor pulmonale, doença de Addison, estenose de laringe ou traquéia, etc.

\section{PESQUISA DE CO-MORBIDADES}

Pacientes com PCM, frequentemente apresentam comorbidades de natureza infecciosa e/ou não infecciosa. Dos processos infecciosos, destacam-se tuberculose, cuja associação é registrada em 5 a $10 \%$ dos casos, enteroparasitoses, exacerbação infecciosa de doença pulmonar obstrutiva crônica e aids. Menos freqüentemente, têm sido relatados casos de aids, leishmaniose, micoses (dermatofitoses, candidíase, cromoblastomicose, esporotricose, histoplasmose clássica e criptococose), hanseníase, lues e doença de Chagas, entre outros. Casos de doenças não infecciosas foram relatados como comorbidades, tais como a doença de Hodgkin e carcinomas associados. Neste contexto, indivíduos que, apesar do uso regular da medicação antifúngica, apresentam resposta clínica insatisfatória devem ser investigados para a presença de comorbidade ou sequiela.

\subsection{Paracoccidioidomicose e aids}

Pouco mais de uma centena de casos de PCM associada à aids foram relatados, na maioria deles com características da forma aguda e disseminada de PCM concomitantemente às características da forma crônica da doença. Este aspecto sugere que as formas clínicas usualmente empregadas em pacientes imunocompetentes não sejam aplicáveis isoladamente à coinfecção PCM/aids. As manifestações clínicas incluem febre prolongada, emagrecimento importante, envolvimento pulmonar, linfoadenopatia generalizada, esplenomegalia, hepatomegalia, e lesões cutâneas e, inclusive, acometimento neurológico. A maior parte dos pacientes com co-infecção PCM e HIV apresenta-se com níveis de linfócitos CD4 inferiores a 200 células/ml e os anticorpos anti-P. brasiliensis estão presentes em apenas $60 \%$ dos casos.

Tendo em vista a limitação dos dados disponíveis, não é possível fazer qualquer recomendação com base em evidências científicas sobre a duração da terapêutica antifúngica nestes pacientes. Contudo, a exemplo de outras infecções fúngicas invasivas de ocorrência em AIDS, sugerese que, em pacientes com estado avançado de aids e manutenção da contagem de células CD 4 abaixo de 200/ml, a droga antifúngica seja mantida indefinidamente. Em pacientes que apresentem controle da infecção pelo HIV, com negativação da carga viral e recuperação de linfócitos CD4 $\geq 200 / \mathrm{ml}$, pode-se considerar a opção de suspensão da 
profilaxia secundária, uma vez atingidos os critérios de cura da PCM. No entanto, são necessários estudos prospectivos para validar esta orientação.

\subsection{Paracoccidioidomicose e câncer}

Há registro na literatura de poucos casos de associação entre PCM e carcinomas, particularmente em localizações como pulmões, orofaringe e laringe. Mais raramente, neoplasias da série hematológica, como leucemia e linfoma, também podem ocorrer. A suspeita diagnóstica é fundamental para o estabelecimento precoce do diagnóstico e da terapêutica. À semelhança do que ocorre na tuberculose, a presença de carcinoma de pulmão em pacientes com PCM pulmonar pode ser mascarada por manifestações decorrentes da fibrose pulmonar consequente à micose. 0 mesmo pode ocorrer em lesões cicatriciais de acometimento de laringe e faringe, particularmente nos pacientes alcoolistas e tabagistas.

\subsection{Condutas práticas em pacientes com PCM e suspeita de co-morbidades}

1. Solicitar pesquisa de BAAR em 3 amostras de escarro em pacientes com quadro de PCM pulmonar, particularmente naqueles com febre e sudorese noturna;

2. Investigar a possível infecção por HIV em pacientes com epidemiologia sugestiva, bem como em casos de PCM com formas disseminadas graves;

3. Fazer acompanhamento otorrinolaringológico de pacientes com lesão laríngea e que persistam com disfonia, para diagnóstico diferencial com tuberculose ou malignização;

4. Em pacientes com envolvimento pulmonar e piora da função respiratória, apesar do tratamento adequado, devese considerar a possibilidade de infecção bacteriana e/ou tabagismo, TB ou neoplasia associados ou evolução para forma sequelar.

\section{SEQÜELAS}

A PCM é uma doença sistêmica, cuja resposta do hospedeiro ao agente infectante consiste de processo inflamatório granulomatoso crônico, que leva à fibrose. Nos estágios mais avançados da resposta inflamatória, há um aumento substancial na produção de citocinas capazes de induzir o acúmulo de colágeno, entre elas TNF-D e TGF-E. 0 acúmulo de colágeno e a formação de fibrose podem levar a alterações anatômicas e funcionais dos órgãos acometidos durante a infecção, particularmente os pulmões. Fibrose pulmonar foi descrita por imagem em cerca de $50 \%$ dos pacientes com infecção crônica deste órgão, evoluindo em menor percentagem com doença pulmonar obstrutiva crônica e suas complicações.
0 envolvimento adrenal tem sido documentado em cerca de 40 a 50\% dos indivíduos submetidos a necropsia. Estudos de avaliação funcional da reserva adrenal mostram que 15 a $50 \%$ dos pacientes podem evoluir com redução da função desta glândula. Cerca de $3 \%$ dos pacientes apresentam doença de Addison necessitando reposição hormonal.

0 sistema nervoso central é comprometido em cerca de 6 a 25\% dos casos de PCM, sendo sua apresentação mais comum representada por lesões expansivas, únicas ou múltiplas, em hemisférios do cérebro, cerebelo ou de ambos. Os pacientes freqüentemente evoluem com déficit motor, síndrome convulsiva (epilepsia) e/ou hidrocefalia. 0 envolvimento cerebelar ocorre em cerca de 20 a $30 \%$ dos casos de neuro-PCM, sendo comum a evolução rápida para hipertensão intracraniana, levando a necessidade de derivação ventricular. 0 potencial de seqüelas das formas neurológicas desta micose é bastante substancial.

Além das seqüelas relacionadas às lesões pulmonares, adrenais e de sistema nervoso central, o processo de fibrose decorrente do envolvimento de mucosas e pele pode causar alterações crônicas de voz (disfonia por lesão de corda vocal), obstrução laríngea com necessidade de traqueostomia, redução da rima bucal e sinéquia de nádegas. Nas formas agudas, as seqüelas mais comuns são obstrução de linfáticos abdominais com síndrome de má absorção e perda de proteínas (linfangectasia intestinal) e quadros de icterícia obstrutiva (Figura 8).

0 custo social e econômico destas complicações não tem sido adequadamente avaliado pela comunidade científica e pelas autoridades de saúde.

\subsection{Proposta de algoritmo de avaliação de seqüiela pulmonar}

Pacientes com PCM, freqüentemente tabagistas, apresentam padrões de insuficiência respiratória de tipo obstrutivo, restritivo ou misto, inferindo-se uma ação sinérgica entre tabagismo e a PMC na gênese da obstrução.
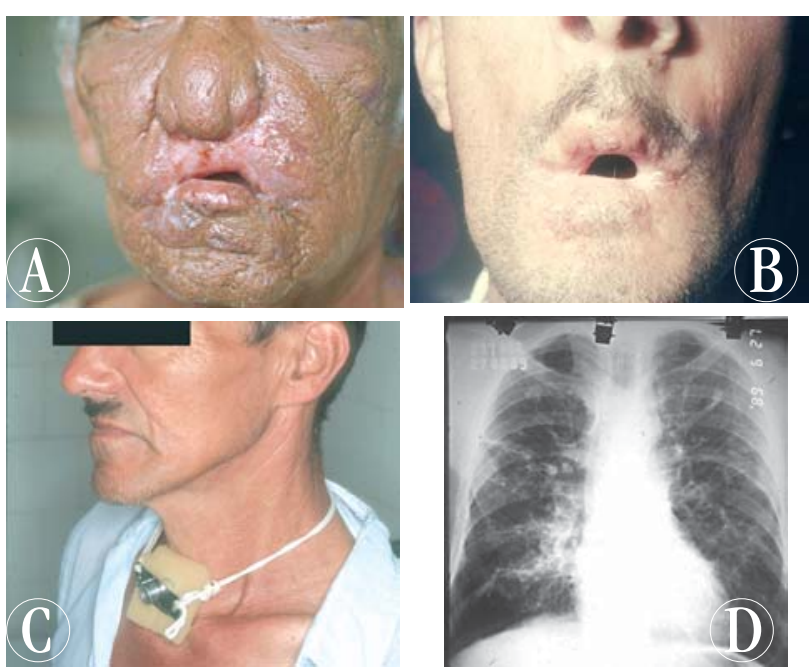

Figura 8 - Seqüelas em paracoccidioidomicose, decorrentes de seu tratamento. A e B Microstomia resultante de lesões peri-orais . C Traqueostomia decorrente de estenose de traquéia. D - Fibrose pulmonar. 
As alterações radiológicas consideradas moderadas e graves estão presentes principalmente em pacientes com quadro funcional obstrutivo. Na gasometria, alguns pacientes podem apresentar $\mathrm{PaCO}_{2}>45 \mathrm{mmHg}$ e hipoxemia $\left(\mathrm{PaO}_{2}<80 \mathrm{mmHg}\right)$. 0 gradiente alvéolo-arterial de $\mathrm{O}_{2}$ pode estar aumentado. A avaliação hemodinâmica pode mostrar hipertensão pulmonar em decorrência de hipóxia.

Após 6 a 9 meses de tratamento da micose (doença controlada), havendo alteração radiológica persistente tais como, a presença de infiltrado intersticial e/ou sinais de hiperinsuflação pulmonar, o paciente deverá ser encaminhado ao pneumologista para estudo funcional dos pulmões (espirometria) e caracterização da gravidade do quadro e orientação da terapêutica.

\section{TRATAMENT0}

0 manejo terapêutico da PCM deve obrigatoriamente incluir medidas de suporte às complicações clínicas associadas ao envolvimento de diferentes órgãos pela micose além da terapêutica antifúngica específica. Os pacientes deverão ser acompanhados periodicamente até apresentarem os critérios de cura. Diferente de outros fungos patogênicos, $P$. brasiliensis é fungo sensível à maioria das drogas antifúngicas, inclusive aos sulfamídicos. Conseqüentemente, vários antifúngicos podem ser utilizados para o tratamento desses pacientes, tais como anfotericina $\mathrm{B}$, sulfamídicos (sulfadiazina, associação sulfametoxazol/trimetoprim), azólicos (cetoconazol, fluconazol, itraconazol).

Apesar da limitação das informações disponíveis em estudos comparativos com diferentes esquemas terapêuticos, sugere-se o itraconazol como a opção terapêutica que permitiria o controle das formas leves e moderadas da doença em menor período de tempo. Entretanto, considerando que o medicamento não está disponível na rede pública da maioria dos Estados, a combinação sulfametoxazol-trimetroprim é a alternativa mais utilizada na terapêutica ambulatorial dos pacientes com PCM. Pacientes com formas graves, necessitando internação hospitalar, devem receber anfotericina $\mathrm{B}$ ou associação sulfametoxazol/ trimetoprim por via intravenosa. A duração do tratamento relaciona-se à gravidade da doença $\mathrm{e}$ ao tipo de droga utilizada. Usualmente, o tratamento é de longa duração, para permitir o controle das manifestações clínicas da micose e evitar as recaídas. 0 paciente deve permanecer em tratamento e acompanhamento até a obtenção dos critérios de cura, com base nos parâmetros clínicos, radiológicos e sorológicos. Além do tratamento antifúngico específico, o paciente deverá receber assistência para as condições gerais como desnutrição, tratamento odontológico, doença de Addison e co-morbidades (tuberculose, aids, enteroparasitoses, infecções bacterianas pulmonares).

Os pacientes com formas graves de PCM, com perda de peso $>10 \%$, associada à dificuldade de deglutição e comprometimento do estado geral, insuficiência respiratória, sinais ou sintomas neurológicos ou evidências de comprometimento de adrenais, devem preferencialmente realizar o tratamento em regime hospitalar. As drogas que podem ser empregadas nestes casos graves são a anfotericina B, na dose de $1 \mathrm{mg} / \mathrm{kg} / \mathrm{dia}$ ou solução intravenosa de sulfametoxazol/trimetoprim, na dose de duas ampolas cada $8 \mathrm{~h}$ até melhora clínica do paciente que permita a introdução da medicação antifúngica oral. 0 voriconazol, um novo antifúngico triazólico de segunda geração, disponível em apresentações oral e intravenosa, apresenta uso potencial em PCM. Sua boa penetração no sistema nervoso central aponta para seu uso na terapêutica da neuroPCM (Tabela 2).

Tabela 2 - Esquema de tratamento ambulatorial para formas leves e moderadas de paracoccidioidomicose ${ }^{*}$

\begin{tabular}{|c|c|c|}
\hline Medicamentos & Dose & $\begin{array}{l}\text { Duração do } \\
\text { tratamento }\end{array}$ \\
\hline Itraconazol ${ }^{* * *}$ & $\begin{array}{l}\text { Adultos: } 200 \mathrm{mg} \text { por dia, logo } \\
\text { após uma das refeições principais } \\
\text { (almoço ou jantar), em uma única } \\
\text { tomada. } \\
\text { Crianças com < 30kg e > } 5 \text { anos, } \\
5 \text { a } 10 \mathrm{mg} / \mathrm{kg} / \text { dia, ajustar a dose não } \\
\text { abrindo a cápsula }{ }^{* * * *}\end{array}$ & $\begin{array}{l}6 \text { a } 9 \text { meses nas } \\
\text { formas leves e } \\
12 \text { a } 18 \text { meses nas } \\
\text { formas moderadas }\end{array}$ \\
\hline $\begin{array}{l}\text { Sulfametoxazol } \\
\text { /trimetoprim*** }\end{array}$ & $\begin{array}{l}\text { Adultos:trimetoprim:160 a 240mg } \\
\text { sulfametoxazol 800mg a 1.200mg. } \\
\text { V012/12hs } \\
\text { Crianças - trimetoprim, } 8 \text { a 10mg/kg } \\
\text { sulfametoxazol, } 40 \text { a } 50 \text { mg/kg, } \\
\text { V0 12/12h }\end{array}$ & $\begin{array}{l}12 \text { meses nas formas } \\
\text { leves e de } 18 \text { a } 24 \\
\text { meses, nas formas } \\
\text { moderadas. }\end{array}$ \\
\hline
\end{tabular}

*Ver item critérios de gravidade. Casos graves devem ser encaminhados a centros de maior resolutividade.

*** Primeira escolha para adultos, com base na facilidade de administração, melhor aderência e tolerabilidade. Crianças que não deglutem cápsulas de itraconazol podem ser tratadas com a solução oral de sulfametoxazol/trimetoprim.

**** Maior experiência em crianças é com sulfametoxazol/trimetoprim.

Observações:

O itraconazol não pode ser utilizado conjuntamente com: astemizol, antiácidos e bloqueadores de receptor $\mathrm{H} 2$, barbituricos, cisapride, ciclosporina, didanosina, digoxina, fentanil, fenitoína, rifampicina, cisaprida e terfenadina.

9.1. Principais interações medicamentosas dos antifúngicos utilizados no tratamento da PCM (Quadros 1 e 2).

\subsection{Terapêutica em populações especiais}

\section{Paracoccidioidomicose e gravidez}

As alterações imunológicas próprias da gestação podem agravar a historia natural de micoses sistêmicas e doenças causadas por patógenos intracelulares. A literatura registra o aumento de ocorrência de abortos e natimortos em gestantes com paracoccidioidomicose. Além disso, foram observadas placentite e intervilosite com trombose nos vasos da placenta de gestantes com PCM, podendo resultar em 
Quadro 1- Interações medicamentosas de sulfamídicos e anfotericina B

Droga antifúngica Outras drogas (B) Efeito interativo entre os Nível de

\begin{tabular}{|c|c|c|c|}
\hline \multicolumn{2}{|l|}{ (A) } & \multirow{2}{*}{$\begin{array}{l}\text { medicamentos } \\
\text { pnível de B }\end{array}$} & ignificância \\
\hline Sulfamídicos & Ciclosporina & & + \\
\hline & Metotrexate & natividade antifolato & + \\
\hline & Anticoagulante oral & $\begin{array}{l}\text { n tempo de protrombina; } \\
\text { ocorrência de sangramento }\end{array}$ & + \\
\hline & Fenitoina & nnível de B; nistagmo; ataxia & + \\
\hline & Rifampicina & $\mathrm{p}$ nível de $\mathrm{A} ; \mathrm{n}$ nível de $\mathrm{B}$ & + \\
\hline & Sulfonil uréira & $\mathrm{n}$ efeito hipoglicemiante & ++ \\
\hline \multirow{10}{*}{$\begin{array}{l}\text { Sulfametoxazol/ } \\
\text { Trimetoprim }\end{array}$} & Azatioprina & Relatos de leucopenia & + \\
\hline & & & \\
\hline & Ciclosporina & $\begin{array}{l}\text { n creatinina sérica; } \\
\text { pnível B }\end{array}$ & + \\
\hline & Loperamida & n nível de $B$ & + \\
\hline & $\begin{array}{l}\text { Anticonceptivos } \\
\text { orais }\end{array}$ & $\mathrm{p}$ efeito de $\mathrm{B}$ & + \\
\hline & Pimozida & $p$ efeito de $B$ & + \\
\hline & Fenitoina & $\mathrm{n}$ efeito de $\mathrm{B}$ & + \\
\hline & Rifampicina & $\mathrm{n}$ efeito de $\mathrm{B}$ & + \\
\hline & Warfarin & $\mathrm{n}$ atividade de $\mathrm{B}$ & + \\
\hline & Metotrexate & $\mathrm{n}$ a supressão da medula & ++ \\
\hline \multirow{4}{*}{$\begin{array}{l}\text { Anfotericina B ou } \\
\text { formulações } \\
\text { lipídicas }\end{array}$} & Antineoplásicos & $\mathrm{n}$ risco nefrotoxicidade & + \\
\hline & & & \\
\hline & Digitálicos & ntoxicidade do digital se $\mathrm{K} \mathrm{p}$ & + \\
\hline & $\begin{array}{l}\text { *Drogas } \\
\text { nefrotóxicas }\end{array}$ & $\mathrm{n}$ toxicidade Anfotericina $\mathrm{B}$ & ++ \\
\hline
\end{tabular}

Nível de significância: + importância provável; ++ importância definida.

*Drogas nefrotóxicas: aminoglicosídeos (amicacina, gentamicina, tobramicina, netilmicina, estreptomicina); ciclosporina; forscarnet; pentamidina; ciclofovir

imaturidade e óbito fetal. 0 alto risco de óbito materno e fetal sugere um manejo mais agressivo nesses casos. As opções terapêuticas são a Anfotericina B, com a qual não há relatos de efeito teratogenico e a associação sulfametoxazoltrimetoprim, seguro após as 4 primeiras semanas da gestação, devendo ser suspensa pelo menos uma semana antes do parto para evitar a ocorrência de kernicterus. Os azólicos não devem ser utilizados pela conhecida ação teratogênica.

\section{Paracoccidioidomicose e insuficiência renal}

0 itraconazol pode ser usado, não havendo necessidade de redução de dose em pacientes com insuficiencia renal. Os derivados sulfamídicos devem ser evitados, assim como anfotericina B pela nefrotoxicidade.

\section{Paracoccidioidomicose e alterações funcionais hepáticas}

Em pacientes com alterações funcionais hepáticas, caracterizadas por enzimas hepatocelulares $>4$ vezes o limite máximo normal, os azólicos devem ser evitados. As sulfas devem ser utilizadas com cautela pois, raramente, podem causar hepatotoxicidade. 0 mesmo deve ser feito quando
Quadro 2 - Interações medicamentosas de azólicos.

\begin{tabular}{|c|c|c|c|c|c|c|}
\hline \multicolumn{4}{|c|}{ Azólicos (A) } & \multirow[b]{2}{*}{ Outras Drogas (B) } & \multirow{2}{*}{$\begin{array}{c}\text { Efeitos interativos } \\
\text { entre } \\
\text { os medicamentos }\end{array}$} & \multirow{2}{*}{$\begin{array}{r}\text { Nível de } \\
\text { Significância }\end{array}$} \\
\hline Flu & Itra & Ceto & Vori & & & \\
\hline+ & + & & & Aminofilina/teofilina & nnível de B & + \\
\hline \multirow[t]{2}{*}{+} & + & + & + & $\begin{array}{l}\text { Bloqueadores de cana } \\
\text { l de cálcio }\end{array}$ & nnível de B & ++ \\
\hline & & & + & $\begin{array}{l}\text { Carbamazepina } \\
\text { (Voriconazol } \\
\text { contraindicado) }\end{array}$ & pnível de A & ++ \\
\hline \multirow[t]{2}{*}{+} & + & + & + & Ciclosporina & $\begin{array}{l}\text { nnível de B; } \\
\text { nrisco de } \\
\text { nefrotoxicidade }\end{array}$ & + \\
\hline & + & + & & $\begin{array}{l}\text { Bloqueadores H2; } \\
\text { anti ácidos; sucalfate }\end{array}$ & pabsorção de A & + \\
\hline \multirow[t]{3}{*}{+} & + & + & + & Fenitoina & $\begin{array}{l}\text { nnível de B; } \\
\text { pnível de A }\end{array}$ & ++ \\
\hline & + & + & & Isoniazida & pnível de A & + \\
\hline & + & & + & Lovastatina/Sivastatina & $\begin{array}{l}\text { nnível de B; } \\
\text { descrição de } \\
\text { rabdomiólise }\end{array}$ & ++ \\
\hline+ & + & + & + & $\begin{array}{l}\text { Midazolan/triazolan } \\
\text { oral }\end{array}$ & nnível de B & ++ \\
\hline+ & + & + & + & Anticoagulante oral & nefeito de B & ++ \\
\hline \multirow[t]{3}{*}{+} & + & & + & hipoglicemiante oral & nnível de B & ++ \\
\hline & + & + & $?$ & Inibidores de protease & nnível de B & ++ \\
\hline & + & + & + & $\begin{array}{l}\text { Inibidores de bomba de } \\
\text { prótons }\end{array}$ & $\begin{array}{l}\text { pabsorção de A; } \\
\text { nnível de B }\end{array}$ & ++ \\
\hline \multirow[t]{2}{*}{+} & + & + & + & $\begin{array}{l}\text { Rifampicina/rifabutina } \\
\text { (Voriconazol contra } \\
\text { indicado) }\end{array}$ & $\begin{array}{l}\text { nnível de B; } \\
\text { pnível de A }\end{array}$ & ++ \\
\hline & & & + & $\begin{array}{l}\text { Sirolimus (voriconazo } \\
\text { l contra indicado) }\end{array}$ & nnível de B & ++ \\
\hline+ & & + & & Tacrolimus & nnível de B & ++ \\
\hline
\end{tabular}

FLU: fluconazol; ITRA: itraconazol; CETO: cetoconazol; VORI: voriconazol . Adaptado de: The Sanford Guide to antimicrobial therapy 2005. 35th edition. D. N. Gilbert, RC Moellering Jr, GM Eliopoulus, MA Sande.

um dos azólicos for indicado, sendo o fluconazol o de menor hepatoxicidade. A anfotericina B desoxicolato pode ser indicada com menos restrições, mas as preparações lipídicas revelam certo grau de hepatoxicidade.

\section{Impossibilidade de uso de medicação oral}

Utilizar apresentação endovenosa: sulfametoxazoltrimetoprim ou anfotericina $\mathrm{B}$.

\section{Paracoccidioidomicose em crianças}

0 medicamento mais usado em crianças é a combinação de sulfametoxazol/ trimetoprim pela eficácia conhecida, boa tolerabilidade e pela facilidade de administração. Este medicamento tem apresentação na forma de xarope, facilitando a adequação de doses, é palatável para as crianças e é fornecido pela rede pública de saúde. A dose recomendada é de 8 a $10 \mathrm{mg} / \mathrm{kg} / \mathrm{dia}$ da 
trimetoprim, em duas tomadas diárias. A formulação endovenosa deve ser usada na mesma dosagem, administrada em 2 a 4 vezes. Entre os efeitos colaterais descritos, a leucopenia é freqüiente, mas pode ser controlada com uso concomitante de ácido folínico, sem outras complicações associadas. Uma grande vantagem é a possibilidade de administração endovenosa quando a via oral não pode ser usada, como nos casos que se apresentam com suboclusão intestinal. 0 itraconazol pode ser usado como segunda opção, na dosagem de 5 a $10 \mathrm{mg} / \mathrm{kg} / \mathrm{dia}$, uma vez ao dia.

\section{CRITÉRIOS DE CURA}

Os critérios de cura em PCM são clínicos, radiológicos e imunológicos.

Clínico: Desaparecimento dos sinais e sintomas da doença, incluindo a cicatrização das lesões tegumentares, involução das linfoadenopatias e recuperação do peso corporal. Freqüentemente, persistem sintomas residuais, decorrentes das sequelas da PCM, especialmente respiratórias, linfático-abdominais, cutâneas, adrenais e neurológicas. Estes sintomas não representam atividade da doença

Radiológico: Estabilização do padrão das imagens cicatriciais radiológicas pulmonares em duas teleradiografias registradas com intervalo de três meses.

Imunológico: Negativação dos títulos de imunodifusão dupla ou estabilização do título em valores baixos, menores ou iguais a 1:2, observadas em duas amostras de soro coletadas com intervalo de seis meses, após o período de tratamento recomendado para itraconazol ou sulfametoxazol/ trimetoprim.

\section{ACOMPANHAMENTO PÓS-TERAPÊUTICO}

A palavra cura talvez nunca possa ser aplicada aos pacientes portadores de PCM pela impossibilidade de erradicação de $P$. brasiliensis. Os pacientes apresentam 0 risco potencial de uma reativação tardia, motivo pelo qual se emprega o termo "cura aparente ou cura clínica". As diferentes modalidades terapêuticas diminuem a quantidade de fungos no organismo, permitindo a recuperação da imunidade celular e restabelecendo o equilíbrio entre parasito e hospedeiro. Por este motivo, após a interrupção do tratamento uma vez observados os critérios de cura, os pacientes devem ser acompanhados ambulatorialmente, uma vez ao ano, com exame clínico e sorológico, se necessário. A positivação ou aumento do valor do título da reação de imunodifusão dupla pode preceder a recaída clínica. Portanto, frente a esta situação está justificada a reintrodução da terapêutica antifúngica e o acompanhamento do paciente, como já descrito na doença ativa.

\section{Agradecimentos}

À UNICAMP, por sediar este consenso. À Disciplina de Infectologia do Depto. de Saúde Comunitária da Universidade Federal do Paraná, à Disciplina de Infectologia do Depto. de Medicina da Escola Paulista de Medicina e ao Depto. de Dermatologia da Faculdade de Medicina de Botucatu da UNESP, pela gentileza em disponibilizar as fotos do presente consenso.

\section{Declaração de potencial conflito de interesse:}

Considerou-se na presente declaração apenas os medicamentos citados neste consenso e que não tiveram quebra de patente nos últimos cinco anos:

Laboratórios Pfizer Ltda

Arnaldo Lopes Colombo - educação continuada, projetos de pesquisa, consultoria/palestra;

Flávio de Queiroz Telles Filho - educação continuada, pesquisa clínica, consultoria/palestra;

Maria Aparecida Shikanai Yasuda - pesquisa clínica;

Maria Luiza Moretti - educação continuada, consultoria/ palestra.

\section{REFERÊNCIAS BIBLIOGRÁFICAS}

\section{Texto: Epidemiologia}

Coutinho ZF, Silva D, Lazera M, Petri V, Oliveira RM, Sabroza PC, Wanke B. Paracoccidioidomycosis mortality in Brazil (1980-1995). Cadernos de Saúde Publica (Rio de Janeiro) 18:1441-1454, 2002. ® [Relata os índices de mortalidade por PCM em todo o Brasil no período de 1980-1995, importante indicador da gravidade desta infecção para o País]

Lacaz CS, Porto E, Martins JEC, Heins-Vaccari EM, Melo NT. Paracoccidioidomicose. In: Lacaz CS, Porto E, Martins JEC, Heins-Vaccari EM, Melo NT (eds) Tratado de Micologia Médica Lacaz, Sarvier Editora de Livros Médicos Ltda., São Paulo, p.639-729, 2002. ® [Excelente capítulo de livro, para revisão do tema]

Restrepo-Moreno A. Ecology of Paracoccidioides brasiliensis. In: Franco MF, Lacaz CS, Restrepo-Moreno A, Del Negro G (eds) Paracoccidioidomycosis, $1^{\text {st }}$ edition, CRC Press, Boca Raton, p.121-130, 1994. ® [Excelente capítulo de revisão sobre a ecologia de Paracoccidioides brasiliensis]

Valle ACF, Wanke B, Wanke N, Peixoto TC, Perez M. Tratamento da paracoccidioidomicose: estudo retrospectivo de 500 casos. I-Análise clínica, laboratorial e epidemiológica. Anais Brasileiros de Dermatologia 67:251-254, 1992. ® [Excelente artigo de revisão sobre epidemiologia, clínica e diagnóstico da PCM, de interesse geral e de dermatologistas]

Wanke B, Londero AT. Epidemiology and paracoccidioidomycosis infection. In: Franco MF, Lacaz CS, Restrepo-Moreno A, Del Negro G (eds) Paracoccidioidomycosis. CRC Press, Boca Raton, p.109-120, 1994. ® [Excelente capítulo de revisão sobre a epidemiologia e PCM-infecção]

\section{Texto: Imunopatogenia}

Benard G, Franco M. Paracoccidoidomycosis. In: Merz WG, Hay RJ (eds) Medical Mycology, Topley's and Wilson's Microbiology and Microbial Infections, $10^{\text {th }}$ edition, Hodder Arnold, London, p.541-559, 2005. Capítulo de livro 


\section{Texto: Microbiologia médica com revisão recente em paracoccidioidomicose}

Borges-Walmsley MI, Chen D, Shu X, Walmsley AR. The pathobiology of Paracoccidioides brasiliensis. Trends Microbiology 2:80-87, 2002. Revisão sobre aspectos da patogenia da doença.

Ferreira, MS, Queiroz-Telles F. Imunopatogênese e Patologia. In: Foccacia R (ed) Tratado de Infectologia, $3^{\mathrm{a}}$. edição, Atheneu Editora, São Paulo, p.13741378, 2005. Revisão compreensiva sobre a imunopatogenia e aspectos patológicos da paracoccidioidomicose

Shikanai-Yasuda MA, Kono A, Magri MM. Imunologia das Micoses. In: Foccacia R (ed) Tratado de Infectologia, $3^{\text {a }}$. edição, Atheneu Editora, São Paulo, p.13131340, 2005. Revisão compreensiva sobre interação hospedeiro parasito na paracoccidioidomicose

\section{Texto: Clínica e Diagnóstico}

Almeida SM, Queiroz-Telles F, Teive HA, Ribeiro CE, Werneck L.C. Central nervous system paracoccidioidomycosis: clinical features and laboratory findings. Journal Infection 48:193-198, 2004.

Barbosa W, Daher R, Oliveira AR. Forma linfático-abdominal da blastomicose abdominal. Revista do Instituto de Medicina Tropical de São Paulo 10:16-27, 1968. Bisinelli JC, Queiroz-Telles F, Sobrinho JA, Rapoport A. Manifestações estomatológicas da paracoccidioidomicose. Revista Brasileira de Otorrinolaringologia 67:683-687, 2001.

Colombo AL, Queiroz-Telles F, Graybill J. Paracoccidioidomycosis. In: Mandell GD, Diamond RD (eds). Atlas of Infectious Diseases. Current Medicine, Ed. Philadelphia, USA, p.54-63, 2000. Capítulo de atlas contendo principais aspectos ilustrados da doença

Del Negro G, Melo EHL, Rodbard D, Melo MR, Layton J, Rodbard HW. Limited adrenal reserve in Paracoccidiodomycosis, cortisol and aldosterone responses to 1-24 ACTH. Clinical Endocrinology 13:553-559, 1980

Londero AT. Paracoccidiodomicose. I. patogenia, formas clínicas, manifestações pulmonares e diagnóstico. Jornal de Pneumologia 12:41-60, 1986.

Londero AT, Ramos CD. Paracoccidiodomicose. Estudo clínico e micológico de 260 casos observados no interior do estado do Rio Grande do Sul. Jornal de Epidemiologia 16:129-132, 1990.

Marques SA. Paracoccidioidomicose: Atualização Epidemiológica, Clínica e Terapêutica. Anais Brasileiros de Dermatologia 78:135-150, 2003.

Martinez R, Meneguelli UG, Dantas R0, Fiorillo AM. O comprometimento gastrintestinal na Blastomicose Sul-Americana (Paracoccidiodomicose). I Estudo clínico, radiológico e histopatológico. Revista Associação Médica Brasileira 25: 31-44, 1979 .

Mendes RP. Bone and joint lesions. In: Franco M, Lacaz CS, Restrepo-Moreno A, Del Negro G (eds) Paracoccidiodomycosis, $1^{\text {st }}$ edition, Boca Raton, CRC Press, p.331-337, 1994. Revisão compreensiva sobre PCM osteo-articular

Texto: Diagnóstico laboratorial e seguimento sorológico

Camargo ZP, Berzaghi R, Amaral CC, Silva SHM. Simplified method for producing Paracoccidioides brasiliensis exoantigens for use in immunodiffusion tests. Medical Mycology 41:539-542, 2003

Del Negro GMB, Pereira CN, Andrade HF, Palacios SA, Vidal MMS, Charbel CE, Bernard G. Evaluation of tests for antibody response in the follow-up of patients with acute and chronic forms of paracoccidioidomycosis. Journal Medical Microbiology 49:37-46, 2000

Martinez R. Other laboratory tests: Hematologic and biochemical chances. In: Franco M, Lacaz CS, Restrepo-Moreno A, Del Negro G (eds) Paracoccidioidomycosis, $1^{\text {st }}$ edition, Boca Raton, CRC Press, p. 365-372, 1994. Revisão compreensiva sobre aspectos laboratoriais da paracoccidioidomicose
Marques da Silva SH, Colombo AL, Blotta MHSL, Lopes JD, Queiroz-Telles F, Camargo ZP. Detection of circulating gp43 antigen in serum, cerebrospinal fluid and bronchoalveolar lavage fluid of patients with paracoccidioidomycosis. Journal Clinical Microbiology 41:3675-3680, 2003.

Mendes Giannini MJS, Bueno JP, Shikanai-Yasuda MA, Stoff AMS, Masuda A, Amato Neto V, Ferreira AW. Antibody response to the $43 \mathrm{kDa}$ glycoprotein of Paracoccidioides brasiliensis as a marker for the evaluation of patients under treatment. American Journal Tropical Medicine Hygiene 43:200-206, 1990.

Panunto-Castelo A, Silva GF, Bragheto IC, Martinez R, Roque-Barreira MC. Paracoccidioides brasiliensis exoantigens: recognition by IgG from patients with different clinical forms of paracoccidioidomycosis. Microbes Infection 5:12051211, 2003.

Valle ACF, Costa RLB, Monteiro PCF, Von Helder J, Muniz MM, Zancopé-Oliveira RM. Interpretation and clinical correlation of serological tests in paracoccidioidomycosis. Medical Mycology 39:373-377, 2001.

\section{Texto: Classificação de formas clínicas}

Benard G, Duarte AJ. Paracoccidioidomycosis: a model for evaluation of the effects of human immunodeficiency vírus infection on the natural history of endemic tropical diseases. Clinical Infectious Diseases 31:1032-1039, 2000.

Franco M, Mendes RP, Moscardi-Bacchi M, Rezkallah-Iwasso M, Montenegro MR. Paracoccidioidomycosis. Baillières Clinical Tropical Medicine Communicable Diseases 4: 185-220, 1989.

Franco M, Montenegro MR, Mendes, RP, Marques SA, Dillon ML, Mota NGS. Paracoccidioidomycosis: a recently proposed classification of its clinical forms. Revista Sociedade Brasileira Medicina Tropical 20:129-132, 1987.

Giraldo R, Restrepo A, Gutierrez F, Robledo M, Londono F, Hernandez H, Sierra F, Calle G. Pathogenesis of paracoccidioidomycosis: a model based on the study of 46 patients. Mycopathologia 58:63-70, 1976.

Mendes RP, Shikanai-Yasuda MA. Paracoccidioidomicose. In: Cimerman S, Cimerman B (eds) Medicina Tropical, $1^{\text {a }}$ edição, São Paulo, Atheneu, p. 505545, 2003. Capítulo de livro contendo revisão atual sobre a doença

\section{Texto: Paracoccidioidomicose e Aids}

Benard G, Duarte AJ. Paracoccidioidomycosis: a model for evaluation of the effects of human immunodeficiency virus infection on the natural history of endemic tropical diseases. Clinical Infectious Diseases 31:1032-1039, 2000. Discussão sobre aspectos imunológicos e correlação com apresentação clínica, e a possível influência da infecção pelo HIV

Goldani LZ, Sugar AM. Paracoccidioidomycosis and AIDS: an overview. Clinical Infectious Diseases 21:1275-1281, 1995. Revisão sobre os casos de coinfecção relatados até o período.

Marques SA, Conterno LO, Sgarbi LP, Villagra AM, Sabongi VP, Bagatin E, Goncalves VL. Paracoccidioidomycosis associated with acquired immunodeficiency syndrome. Report of seven cases. Revista Instituto Medicina Tropical São Paulo 37:261-265, 1995.

Pedro RJ, Aoki FH, Boccato RSB, Branchini MLM, Gonçales Jr. FL, Papaiordanou PMO, Ramos MC.- Paracoccidioidomicose e infecção pelo vírus da imunodeficiência humana. Revista Instituto Medicina Tropical São Paulo 31:119125,1989. Primeiro caso relatado de PCM em paciente com Aids

Silva-Vergara ML, Teixeira AC, Curi VG, Costa Junior JC, Vanunce R, Carmo WM, Silva MR. Paracoccidioidomycosis associated with human immunodeficiency virus infection. Report of 10 cases. Medical Mycology 41:259-263, 2003.

\section{Texto: Paracoccidioidomicose e neoplasias e paracoccidioidomicose e transplantes}

Leão RC, Mendes E. Paracoccidioidomycosis, neoplasia and associated infections. Allergologia Immunopathologia (Madri) 8(3):185-198, 1980.

Marques SA, Shikanai-Yasuda MA. Paracoccidioidomycosis associated sith immunosuppression, Aids and cancer. In: Franco M, Lacaz CS, Restrepo-Moreno A, 
Del Negro G (eds) Paracoccidioidomycosis, $1^{\text {st }}$ edition, CRC Press, Boca Raton, p. 393-405, 1994. Revisão da literatura sobre associação de PCM e câncer até o período, com ênfase na relação entre a micose e câncer.

Shikanai-Yasuda MA, Duarte MI, Nunes DF, Lacaz CS, Sabagga E, Abdala E, Duarte AJ, Lopes MH. Paracoccidioidomycosis in a renal transplant recipient. Journal Medical Veterinary Mycology 33:411-414, 1995.

Sugar AM, Restrepo A, Stevens DA. Paracoccidioidomycosis in the immunosupressed host: report of a case and review of the literature. American Review Respiratory Diseases 129:340-342, 1984. 0 primeiro relato de caso de associação de PCM e Transplante.

Valle AC, Asprigliano Filho F, Moreira JS, Wanke B. Clinical and endoscopic findings in the mucosae of the upper respiratory and digestive tracts in posttreatment follow-up of paracoccidioidomycosis patients. Revista Instituto Medicina Tropical São Paulo 37:407-413, 1995

Zavascki AP, Bienardt JC, Severo LC. Paracoccidioidomycosis in organ transplant recipient: case report. Revista Instituto Medicina Tropical São Paulo 46:279-281, 2004.

\section{Texto: Tratamento da paracocidioidomicose.}

Guerreiro CAM, Chuluc SSD, Branchini MLM. A new treatment for large cerebral paracocidioidomycosis. Arquivos de Neuropsiquiatria 45:419-423,1987.

Marques S. Paracoccidioidomciose. Tratamento com itraconazol. Resultados obtidos após longo prazo de seguimento. Tese de Livre-Docência, Faculdade de Medicina de Botucatu, 1998.

Marques SA, Dillon NL, Franco MF, Habermann MC, Lastoria JC, Stolf HO, Marcondes J, Grizzo W, Silva NC, Cavariani MR. Paracoccidioidomycosis: a comparative study of the evolutionary serologic, clinical and radiologic results for patients treated with ketoconazole or amphotericin B plus sulfonamides. Mycopathologia 89:19-23, 1985.

Naranjo MS, Trujillo M, Munera MI, Restrepo P, Gómez I, Restrepo A. Treatment of paracoccidioidomycosis with itraconazol. Journal Medical Veterinary Mycology 28:67-76, 1990.

Queiroz-Telles F. Tratamento da Paracoccidioidomicose. In: Foccacia R (ed) Tratado de Infectologia, $3^{a}$ edição, Atheneu Editora, São Paulo, p.1395-1402, 2005. Uma atualização recente sobre a terapêutica da paracoccidioidomicose

Shikanai-Yasuda MA, Higaki, Y, Del Negro GB, HO Joo, S, Vaccari ME, Benard G, Gryschek RCB, Segurado AA, Bueno JP, Barone A, Andrade D, Amato Neto V. Randomized therapeutic trial with itraconazole, ketoconazole and sulfadiazine in paracoccidioidomycosis. Medical Mycology 40:411-417, 2002.

Shikanai-Yasuda MA. Pharmacological management of paracoccidioidomycosis. Expert Opinion Pharmacotherapy 6:385-397, 2005. Uma revisão recente sobre a terapêutica da paracoccidioidomicose

Valle ACF, Wanke B, Wanke N, Peixoto TC, Perez M. Tratamento da paracoccidioidomicose. Estudo retrospectivo de 500 casos. Avaliação dos resultados terapêuticos com sulfanilamídicos, anfotericina $\mathrm{B}$, associação sulfametoxazol, trimetoprima, cetoconazol e miconazol. Anais Brasileiros Dermatologia 66:65:70, 1993

Valle AC, Aprigliano Filho F, Moreira JS, Wanke B. Clinical and endoscopic findings in the mucosal of the upper respiratory and digestive tracts in posttreatment follow-up of paracoccidioidomycosis patients. Revista Instituto Medicina Tropical São Paulo 37:407-413, 1995

Texto: Tratamento da paracoccidioidomicoses na gravidez e em situações especiais

Blotta MHSL, Altemani AM, Amaral E, Silva LJ, Camargo ZP. Placental involvement in paracoccidioidomycosis. Journal Medical Veterinary Mycology 31:249-257, 1993
Carvalho MGF, Montenegro MR. Experimental paracoccidioidomycosis in hamsters: Gestational interactions. Mycopathologia 145: 81-87, 1999.

Weinberg ED. Pregnancy-Associated Depression of Cell-Mediated Immunity. Review Infectious Diseases 6: 814-831, 1984.

Franco M, Peraçoli MT, Soares A, Montenegro MR, Mendes RP, Meira DA. Host-parasite relationship in Paracoccidioidomycosis. Currents topics in medical mycology 5:115-149, 1993.

Braga LFCO, Kasting G, Franke HJ. Placentite intervilosa Paraccoccidioidomicótica. Revista. Brasileira Ginecologia Obstetrícia 6:117-120, 1989.

Tavares W. Manual de antibióticos e quimioterápicos anti infecciosos. $3^{\circ}$ edição. São Paulo, Atheneu, p.269-349, 2001.

Texto: Tratamento da paracoccidioidomicose na criança

Benard G, Orii NM, Marques HH, Mendonça M, Aquino MZ, Campeas AE, Del Negro GB, Durandy A, Duarte AJ. Severe acute paracoccidioidomycosis in children. Pediatric Infectious Diseases Journal 13: 510-515, 1994.

Fonseca E, Pardal PO, Severo LC. Paracoccidioidomicose em crianças em Belém do Pará. Revista Sociedade Brasileira Medicina Tropical 32: 31-35, 1999.

Londero AT, Rios-Gonçalves AJ, Terra GMF et al. Paracoccidioidomycosis in Brazilian children. A critical review (1911-1994). Arquivos brasileiros Medicina 70:197-203, 1996

Pereira RM, Bucaretchi F, Barison EM, Hessel G, Tresoldi AT. Paracoccidioidomycosis in children: clinical presentation, follow-up and outcome. Revista do Instituto Medicina Tropical São Paulo 46:127-131, 2004.

Shikanai-Yasuda MA. Pharmacological management of paracoccidioidomycosis. Expert Opinion Pharmacotherapy 6:385-397, 2005.

\section{Texto: Seqüielas}

Bethlem EP, Capone D, Maranhao B, Carvalho CR, Wanke B. Paracoccidioidomycosis. Current Opinion Pulmonary Medicine 5:319-325, 1995. Campos EP, Padovani CR, Cataneo, AM. Paracoccidioidomicose: estudo radiológico e pulmonar de 58 casos. Revista Instituto Medicina Tropical São Paulo 33: 267-276, 1991.

Colombo AL, Faical S, Kater CE. Systematic evaluation of the adrenocortical function in patients with paracoccidioidomycosis. Mycopathologia 127:89-93, 1994.

Del Negro G, Melo EHL, Rodbard MD, Melo MR, Layton J, Wachslicht-Rodbard Limited adrenal reserve in paracoccidioidomycosis: cortisol and aldosterone responses to 1-24 ACTH Clinical Endocrinology 13:553-559, 1980.

Franco L, Najvar L, Gomez BL, Restrepo S, Graybill JR, Restrepo A. Experimental pulmonary fibrosis induced by $P$. brasiliensis conidia: measurement of local host responses. American Journal Tropical Medicine Hygiene 58:424-430, 1998. Funari M, Kavakama J, Shikanai-Yasuda MA, Castro LG, Bernard G, Rocha MS, Cerri GG, Muller NL. Chronic pulmonary paracoccidioidomycosis (South American blastomycosis): high-resolution CT findings in 41 patients. American Journal Roentgenology 173:59-64, 1999.

Tobón AN, Agudelo CA, Osorio ML, Alvarez DL, Arango M, Cano LE, Restrepo A. Residual pulmonary abnormalities in adult patients with chronic paracoccidioidomycosis: prolonged follow-up after itraconazole therapy. Clinical Infectious Diseases 37:898-904, 2003. 


\section{PARTICIPANTES do CONSENSO}

Adriana Satie Kono

Antonia Teresinha Tresoldi

Arnaldo Colombo

Bodo Wanke

Carlos Roberto Carvalho

Flávio de Queiroz Telles Filho

Gil Benard

Luis Carlos Severo
Marcelo Simão Ferreira

Maria Aparecida Shikanai-Yasuda

Maria Luiza Moretti

Mário Leon Silva-Vergara

Rinaldo Pôncio Mendes

Roberto Martinez

Rogério de Jesus Pedro

Sílvio Alencar Marques

Zarifa Khoury 